\section{Original Research}

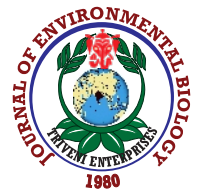

DOI : http://doi.org/10.22438/jeb/41/2(SI)/JEB-18

\title{
Modeling soil erosion in the Chagan river basin of the west Kazakhstan with using RUSLE and GIS tools
}

\author{
T. Darbayeva ${ }^{1}$, N. Ramazanova ${ }^{2}$, B. Chashina ${ }^{2}$, Zh. Berdenov ${ }^{2 *}$, E. Mendybayev ${ }^{3}$, J.A. Wendt ${ }^{4}$ and E. Atasoy ${ }^{5}$ \\ 'Department of Biology and Ecology, West Kazakhstan University (named after M. Utemisov), Uralsk, L02A8Y0, Kazakhstan \\ ${ }^{2}$ Department of Geography, Faculty of Natural Sciences, L.N.Gumilyov Eurasian National University, Astana, 010009, Kazakhstan \\ ${ }^{3}$ Department of Ecology, Faculty of Natural Science, K.Zhubanova Aktobe Regional State University, Aktobe 120505, Kazakhstan \\ ${ }^{4}$ Institute of Geography, Faculty of Oceanography and Geography, Gdansk University, Gdansk, 80309, Poland \\ ${ }^{5}$ Department of Primary Education and Social Sciences, Faculty of Education, Bursa Uludag University, Bursa 16059, Turkey \\ *Corresponding Author Email : berdenov-z@mail.ru
}

\section{Abstract}

Aim: The paper focuses on the soil erosion, which is one of the most important agricultural problems in Kazakhstan. The aim of the study is to evaluate and map the erosion-free zone for the preservation of the water reservoir and quality soils in the Chagan River basin in the region of Western Kazakhstan. Thanks to this, it will be possible to implement erosion prevention measures.

Methodology: In the study, the RUSLE formula was used to determine soil erosion to assess and map soil erosion processes in the studied region. The RUSLE formula has been integrated with the use of GIS includes various settings. The research presents an algorithm for detecting soil treatment in the Chagan river basin using geoinformation systems.

Results: The research allowed to assess the soil erosion rate. The erosion rate on $67 \%$ of the area in the Chagan River basin is $0-0.01$ tons ha $\mathrm{yr}^{-1} \mathrm{rr}^{-1}$, at $23 \%-0.1-0.5$ tons ha ${ }^{-1} \mathrm{yr}^{-1}$, at $5 \%-0.5-1 \%-2$ tons ha $^{-1} \mathrm{yr}^{-1}$, at $3 \%-1.2-2.5$ tons ha ${ }^{-1} \mathrm{yr}^{-1}$, only $2 \%$ of the river basin erosion occurs at the level of 2.5 to 13 tons ha ${ }^{-1} \mathrm{yr}^{-1}$.

Interpretation: Based on the trend of annual loss of soil erodibility in the Chagan River basin, it has identified the need for preventive and remediation measures in the area. The study showed that GIS methods allowed accurate definition of spatial distribution of RUSLE parameters. It is also a simple and cheap tool for soil erosion modelling, the risk for erosion potential and risk for the hazardous area that can be difficult to observe on the ground.

Key words: Geoinformation systems, River basin, RUSLE, Soil erosion

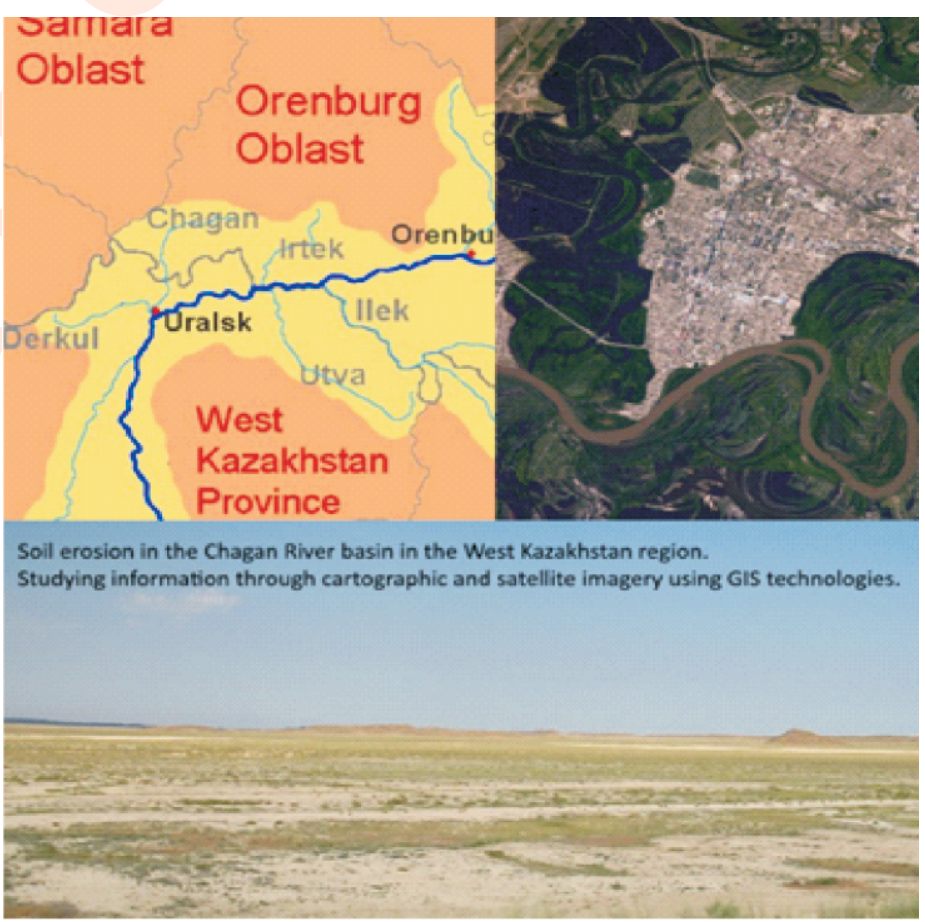

How to cite : Darbayeva, T., N. Ramazanova, B. Chashina, Zh. Berdenov, E. Mendybayev, J.A. Wendt and E. Atasoy: Modeling soil erosion in the Chagan river basin of the west Kazakhstan with using RUSLE and GIS tools. J. Environ. Biol., 41, 396-404 (2020). 


\section{Introduction}

Soil erosion is one of the most intense and widespread geomorphological processes that has a significant adverse effect on land resources and environment as well as on national economy (Borrelli et al., 2016; Nearing et al., 2017). It leads soil degradation and threatens biodiversity, agricultural production and food security (Bargali et al., 1993, 2019; Padalia et al., 2018). Protection of land resources from erosion processes is important part of nature protection and rehabilitation (Petek et al., 2018; Panagos et al., 2019). Intensive erosive processes can be expected as a result of the development of virgin lands, road construction, industrial facilities, hydraulic structures after the war years in West Kazakhstan (lorgansky and Balgabekov, 1979). According to the research results, total area of eroded land was 3967.2 thousand hectares, this means $26.3 \%$ of all territory of Kazakhstan. In addition, the planned change of the river industry leads to the unloading of settlements, roads and pipelines. Soil erosion is a relatively imperceptible ongoing process, or it can form in dangerous quantities, resulting in severe soil loss. Loss of soil from agricultural lands may lead to lower plant potential, damage drainage networks and reduce groundwater quality. Accelerated erosion caused by anthropogenic environmental changes on the global scale results in reservoirs sedimentation, river morphology change, and riverbed sediments (Prasad et al., 2014). Soil erosion depends on various factors; climate, topography, soil characteristics and plants (Kuznetsov and Glazunov; 1992). Several models have been developed to assess the risk of erosion, as the most common model is USLE (Demczuk and Gile; 2009). The Universal Soil Loss Equation (USLE) developed Wischmeier and Smith, 1978) field model for the first time in the 1960s in the United States Department of Agriculture. Later in 1997, RUSLE has developed to better estimation values of various parameters in USLE (the universality of soil loss is revised). RUSLE improves new and better datadriven factors, but relies on the USLE equation. In this study, RUSLE model is used to estimate soil loss from the Chagan River basin of the West Kazakhstan region. All factor maps are created in the GIS platform. The RUSLE model must be combined with the GIS to detect all model parameters (Efe et al., 2008; Efe et al., 2012).These technologies save on the cost of field research and traditional decentralization and increase the accuracy and specificity of mapping (Renard et al., 1997). The relevance of the work is the development of modeling and mapping of soil erosion in the area of the basin by processing of cartographic and space shooting information using GIS technologies. The main goal of the study is to determine the patterns of development of the soil erosion process, the features of the emergence of the process of soil erosion on the example of the Chagan river basin in the West Kazakhstan region using GIS technology.

\section{Materials and Methods}

The Chagan river basin is a tributary of the Irtysh River. Chagan is a cross-border river, which is the administrative center of the Taskala, Zelenovsk districts and West Kazakhstan region, occupying the city of Uralsk and Pervomaisk district of the Orenburg region of the Russian Federation (Garifolla and Akhmetov, 2010).

The basin extends $131 \mathrm{~km}$ north to south and $168 \mathrm{~km}$ west to the east. The area of the Chagan River basin is $7567.1 \mathrm{~km}^{2}$ (occupies $3.3 \%$ of the Ural River basin), the area of the Kazakhstan is $3817.3 \mathrm{~km}^{2}$, the area of the Russia is $3749.8 \mathrm{~km}^{2}$ (Beisenova, 2001).

The physical and geographical location of the Chagan River basin is characterized by the following characteristics. The coordinates of the Chagan River basin are $52^{\circ} 13^{\prime}$ and $51^{\circ} 3^{\prime} \mathrm{N}$ and $49^{\circ} 58^{\prime}$ and $52^{\circ} 24^{\prime} E$. Geographical center of the territory $51^{\circ} 38^{\prime} 14^{\prime \prime} \mathrm{N}$ and $51^{\circ} 10^{\prime} 44^{\prime \prime} \mathrm{E}$.In the North-Western and Western parts of the basin it borders with the basin of the Ulken Yrgyz river, in the North-East - with the basin of the Buzlyk river, in the Eastern part-with the basin of the Yrtyk river (Irtek), in the South-East and in the South-with the basin of small rivers flowing into the Ural river with a common extraction beginning, in the South-West-with the basins of the Chizha-Durin-Balykty. The Chagan river basin is located in the inner region of the Eurasian continent and 2.5 thousand $\mathrm{km}$ from the Atlantic Ocean and its seas. Consequently, it is also far from the Arctic Ocean. This, in turn, contributes to the continental climate of the region. The basin is located in the Southeastern edge of the East European plain between the Edil and the Jaiyk. According to the geological structure of the Chagan river basin occupies the South-Eastern edge of the East European plain and the Northern part of the Caspian syneclise. In the geomorphology of the basin, the area of the basin is represented by the Jalpy Syrt and Uralsk plateau. Relief is flat and the raised part of the array corresponds to the structure of Jalpy Syrt $254 \mathrm{~m}$. (Petrenko, 2001). It is located in the town of Ichka, in the Derkul River basin. The lower part of the basin is equal to the boundary of the Chagan river valley, $23 \mathrm{~m}$ above sea level. The Chagan River basin is located in moderate continental and continental climate zones of temperate climate zone. Accordingly, the basin is characteristic of forest steppe and steppe nature zones. In addition, the forest steppe, to a large extent, facilitates the process of soil erosion (Ramazanova et al., 2019), unlike forestareas.

In determining the Chagan River basin, the model DEM (2012) based primarily on SRTM space shooting was downloaded. The next step was to find out and describe the river basin with the help of the ArcGIS 10.1 program «Hydrology» in the Spatial Analyst Tools function. The following items specified in table 1 were performed during the work execution:

After identification the area of the Chagan River basin, the area of the rivers basin and arable land was determined using the CON application. Carrying out the stages of works specified in the table, maps of definition of surface waters and river basins on a 
Table 1: Hydrographic mapping stages

\begin{tabular}{lll}
\hline Basis & Program function & Results \\
\hline $\begin{array}{l}\text { Topographic map } \\
\text { and DEM model }\end{array}$ & Spatial analyst tools & $\begin{array}{l}\text { The occupied territory of the rivers, the direction of the rivers, zones of sedimentation of slopes } \\
\text { in them are defined using the dimensional model of relief }\end{array}$ \\
$\begin{array}{l}\text { Spatial Analyst Tools and Conditional Tools } \\
\text { After determining the river valley, using the application CON determined the area of rivers and } \\
\text { their basins }\end{array}$ \\
\hline
\end{tabular}

Table 2 : Stages of determining soil erodibility process

\begin{tabular}{llll}
\hline The basis & Program function & Determined factors & Received results \\
\hline DEM model of the Shagan river & Spatial Analyst Tools - Map & $\mathrm{A}$ & soil loss \\
basin, soil map of mechanical soil, & Algebra - Raster Calculator & $\mathrm{R}$ & rainfall erosivity factor \\
map of agricultural lands, map of & & $\mathrm{K}$ & soil erodibility factor \\
construction & $\mathrm{L}$ & slope length \\
& & $\mathrm{S}$ & steepness factor \\
& $\mathrm{C}$ & cover and management factor \\
& & $\mathrm{P}$ & support practice factor \\
\hline
\end{tabular}

scale of 1:200000 were made. In addition, the Chagan river basin has been identified by the following methods of the addition of Hydrology in the program ArcGIS 10.1 to the Spatial Analyst Tools: fill, flow direction, flow accumulation, raster calculator, stream order, interpolate shape and watershed.

In this study, the samples of the RUSLE (Revised Universal Soil Loss Equation) were used to estimate soil loss from watershed (Renard et al., 1994; Renard and Freimund, 1994). The RUSLE model was developed as an equation that reflects the main factors that affect soil erosion - climate, soil characteristics, topography, and surface characteristics (Hernando and Romana, 2016). The equation is as follows:

$$
A=R * K * L * S * C * P
$$

Where: A-soil loss; R-rainfall erosivity factor; K-soil erodibility factor; L-slope length; S-steepness factor; C-cover and management factor; $P$-support practice factor

The essence of the formula allows for the quantitative assessment of the major soil condition factors (rainfall index, soil erosion), creating appropriate factor maps and developing an integrated soil-cleaning map on its basis. Such a map will not only show the scale of the erosion process but also will determine the environmental consequences of erosion (Mendybayev et al., 2015).

It was possible to describe fully the process of soil erodibility in the Chagan river basin with the help of the program «Map Algebra» in the Spatial Analyst Tools function of the ArcGIS 10.1 program (Amirzhanova et al., 2017).

The details of the above factors and their impacts on soil erosion processes are given below. At performance of works the following points specified in table 2 were executed (Wischmeier and Smith, 1978).

\section{Results and Discussion}

The RUSLE factor was used to determine the erosion of the relief surface. Basic information about the RUSLE factor is well described in literature. The values of the RUSLE factor are given below.

R-The rainfall erosivity : Precipitation data collected for 12 years to determine $\mathrm{R}$ factor. After collecting the data, the $\mathrm{R}$ factor was determined for all measurement stations selected using the following equations ( $\mathrm{Xu}, 2008)$. Then, the average $\mathrm{R}$ factor for each precipitation station was introduced into ArcGIS. All data were interpolated in space using the IDW on the Spatial Analyst tool of ArcGIS.

In most cases, rainfall data are very limited; therefore, an attempt was made to detect erosion from seasonal rainfall data. The use of rainfall data in the study area has been identified. The average annual rainfall in the study area corresponds to $90 \mathrm{~mm}$ according to the data obtained from the meteorological station.

K - soil erodibility : Soil erosion, namely the factor $\mathrm{K}$ in West Kazakhstan and 1970-1980 the chief specialist in the scale 1: $10000,1: 25000$, based on the soil map created by Morozov. The quantitative value of the factor $\mathrm{K}$ is obtained from the map of the mechanical composition of the soils, with the help of Wischmeier and Smith (1978) and the map of the Chagan river basin were derived from the map of soil mechanical composition (Fig. 1, 2). As a result, the soil erodibility coefficient of the Chagan river basin has been determined.

Dark brown soils are most common soil type in the Chagan River basin. There are also the following types of soils found in the basin (Bigaliyev and Zhamalbekov, 1995): dark brown carbonate, dark brown saline, floating bog, light gray, meadow swampy; meadow grass and meadow gray. 


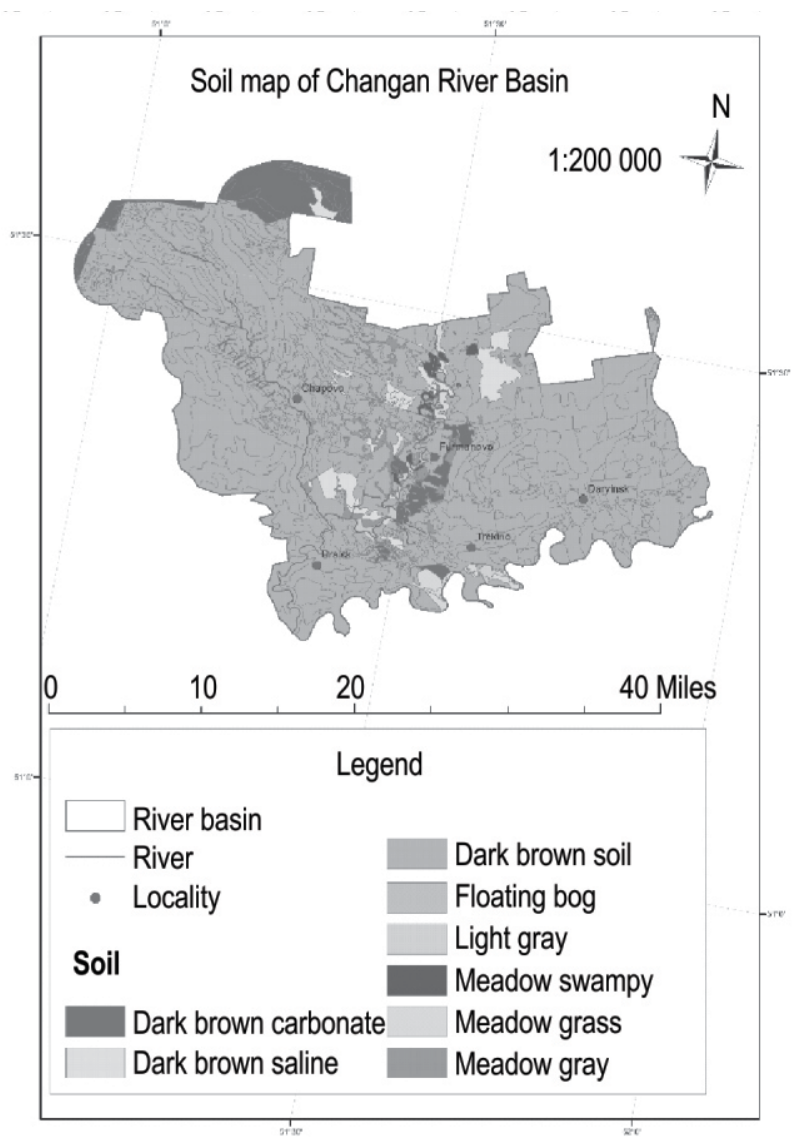

Fig. 1 : Soil map of Chagan River Basin.

After determining the soil types of the Chagan River basin, a map was created by mechanical composition of soil to calculate the factor $\mathrm{K}$, generate the values (URL -2$)$, and we determined the soil erodibility coefficient. Take the obtained coefficients in the attributes table of ArcGIS 10.1 and define the soil wash indicator. The map of the soil composition of the Chagan River basin was analysed and the following information was obtained. About $32 \%$ of the total arbor was found in medium loam, $28 \%$ heavily loam, $21 \%$ clay, $11 \%$ light loam, $6 \%$ loam, $1 \%$ sand and $1 \%$ of loamy sand. By analyzing the obtained map, we created the erosion coefficient, classifying the soil of the Chagan river basin into several classes (URL, 2; Fig. 3).

Seven soil structures were identified and they are involved in the soil erodibility process in the study area. It gave the following values $K=0.26$ for clay, $K=0.02$ for sands, $K=0.28$ for medium loam, $K=0.04$ for loamy sand, $K=0.12$ for light loam, heavy loam for $K=0.37$ and for $K=0.28$ loam. The coefficient of adaptation for the process of average soil loam erosion is $32 \%$ of the basin of the river Chagan is 0,$28 ; 28 \%$ in heavy loam 0,37 ; $21 \%$ clay in the basin is 0,$26 ; 11 \%$ in light loam is 0,$12 ; 6 \%$ clay loam is a measure of the factor of $0.28 ; 1 \%$ in sandy areas is 0,02 ; $1 \%$ in sandy basin is $1 \%$, of which the factor of 0.04 .

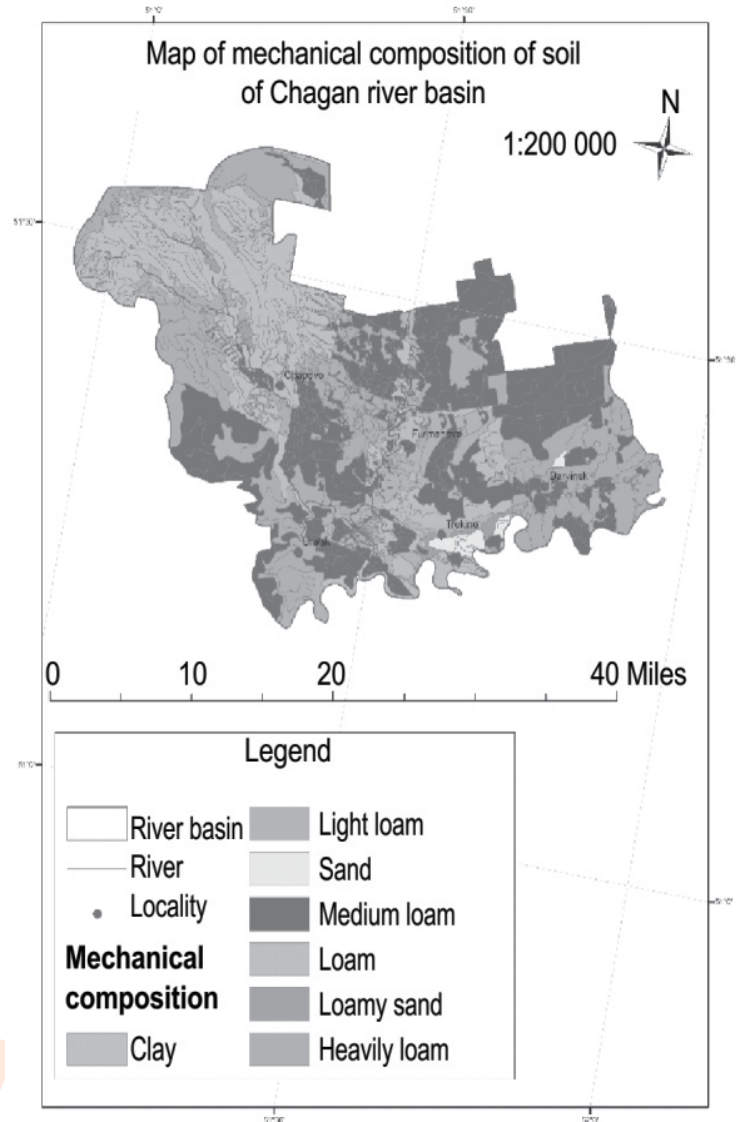

Fig. 2 : Map of mechanical composition of soil of the Chagan river basin.

LS factor. L - slope length; S - steepness factor: The most important indicators of erosion hazard are steepness, shape and exposure of mountain slopes. Slope up to $2^{\circ}(3.5 \%)$ is sometimes called erosion limit. However, it can also occur on low slopes, depending on the soil, its moisture content, the nature of the surface (roughness) and the intensity of precipitation. For a specific area, the weighted average slope is calculated. Surface length is also important. If it is larger, the risk of erosion is greater, especially at the bottom of the surface. There are appropriate coefficients reflecting the ratio of surface length to erosion risk. They are regional and local in nature.

The Program ArcGIS 10.1 and space imaging 2012 (file DEM) to calculate the ratio of length and slope for determining factor LS.

In order to determine the LS factor of the basin the S - coefficient was released. The 3D Analyst Tools function in the Arc Toolbox and Raster Surface from among the operations were selected. After this, the slope was defined using the Slope operation and the original DEM file sample map (Mazhitova et al., 2018). As a result, map was created field (Fig.4). 


\begin{tabular}{|c|c|c|c|c|c|c|c|c|c|c|c|c|c|c|c|c|c|}
\hline \multicolumn{18}{|c|}{ Horizontal Slope Length (ft.) } \\
\hline 1 & 2 & 3 & 4 & 5 & 6 & 7 & 8 & 9 & 10 & 11 & 12 & 13 & 14 & 15 & 16 & 17 & 18 \\
\hline $\begin{array}{l}\text { Slope } \\
(\%)\end{array}$ & $<3$ & 6 & 9 & 12 & 15 & 25 & 50 & 75 & 100 & 150 & 200 & 250 & 300 & 400 & 600 & 800 & 1,000 \\
\hline 0.2 & 0.05 & 0.05 & 0.05 & 0.05 & 0.05 & 0.05 & 0.05 & 0.05 & 0.05 & 0.05 & 0.05 & 0.05 & 0.05 & 0.05 & 0.06 & 0.06 & 0.06 \\
\hline 0.5 & 0.07 & 0.07 & 0.07 & 0.07 & 0.07 & 0.08 & 0.08 & 0.08 & 0.09 & 0.09 & 0.09 & 0.09 & 0.09 & 0.10 & 0.10 & 0.10 & 0.10 \\
\hline 1.0 & 0.11 & 0.11 & 0.11 & 0.11 & 0.11 & 0.12 & 0.13 & 0.14 & 0.14 & 0.15 & 0.16 & 0.17 & 0.17 & 0.18 & 0.19 & 0.20 & 0.20 \\
\hline 2.0 & 0.17 & 0.17 & 0.17 & 0.17 & 0.17 & 0.19 & 0.22 & 0.25 & 0.27 & 0.29 & 0.31 & 0.33 & 0.35 & 0.37 & 0.41 & 0.44 & 0.47 \\
\hline 3.0 & 0.22 & 0.22 & 0.22 & 0.22 & 0.22 & 0.25 & 0.32 & 0.36 & 0.39 & 0.44 & 0.48 & 0.52 & 0.55 & 0.60 & 0.68 & 0.75 & 0.80 \\
\hline 4.0 & 0.26 & 0.26 & 0.26 & 0.26 & 0.26 & 0.31 & 0.40 & 0.47 & 0.52 & 0.60 & 0.67 & 0.72 & 0.77 & 0.86 & 0.99 & 1.10 & 1.19 \\
\hline 5.0 & 0.30 & 0.30 & 0.30 & 0.30 & 0.30 & 0.37 & 0.49 & 0.58 & 0.65 & 0.76 & 0.85 & 0.93 & 1.01 & 1.13 & 1.33 & 1.49 & 1.63 \\
\hline 6.0 & 0.34 & 0.34 & 0.34 & 0.34 & 0.34 & 0.43 & 0.58 & 0.69 & 0.78 & 0.93 & 1.05 & 1.16 & 1.25 & 1.42 & 1.69 & 1.91 & 2.11 \\
\hline 1 & 2 & 3 & 4 & 5 & 6 & 7 & 8 & 9 & 10 & 11 & 12 & 13 & 14 & 15 & 16 & 17 & 18 \\
\hline 8.0 & 0.42 & 0.42 & 0.42 & 0.42 & 0.42 & 0.53 & 0.74 & 0.91 & 1.04 & 1.26 & 1.45 & 1.62 & 1.77 & 2.03 & 2.47 & 2.83 & 3.15 \\
\hline 10.0 & 0.46 & 0.48 & 0.50 & 0.51 & 0.52 & 0.67 & 0.97 & 1.19 & 1.38 & 1.71 & 1.98 & 2.22 & 2.44 & 2.84 & 3.50 & 4.06 & 4.56 \\
\hline 12.0 & 0.47 & 0.53 & 0.58 & 0.61 & 0.64 & 0.84 & 1.23 & 1.53 & 1.79 & 2.23 & 2.61 & 2.95 & 3.26 & 3.81 & 4.75 & 5.56 & 6.28 \\
\hline 14.0 & 0.48 & 0.58 & 0.65 & 0.70 & 0.75 & 1.00 & 1.48 & 1.86 & 2.19 & 2.76 & 3.25 & 3.69 & 4.09 & 4.82 & 6.07 & 7.15 & 8.11 \\
\hline 16.0 & 0.49 & 0.63 & 0.72 & 0.79 & 0.85 & 1.15 & 1.73 & 2.20 & 2.60 & 3.30 & 3.90 & 4.45 & 4.95 & 5.86 & 7.43 & 8.79 & 10.02 \\
\hline 20.0 & 0.52 & 0.71 & 0.85 & 0.96 & 1.06 & 1.45 & 2.22 & 2.85 & 3.40 & 4.36 & 5.21 & 5.97 & 6.68 & 7.97 & 10.23 & 12.20 & 13.99 \\
\hline 25.0 & 0.56 & 0.80 & 1.00 & 1.16 & 1.30 & 1.81 & 2.82 & 3.65 & 4.39 & 5.69 & 6.83 & 7.88 & 8.86 & 10.65 & 13.80 & 16.58 & 19.13 \\
\hline 30.0 & 0.59 & 0.89 & 1.13 & 1.34 & 1.53 & 2.15 & 3.39 & 4.42 & 5.34 & 6.98 & 8.43 & 9.76 & 11.01 & 13.30 & 17.37 & 20.99 & 24.31 \\
\hline 40.0 & 0.65 & 1.05 & 1.38 & 1.68 & 1.95 & 2.77 & 4.45 & 5.87 & 7.14 & 9.43 & 11.47 & 13.37 & 15.14 & 18.43 & 24.32 & 29.60 & 34.48 \\
\hline 50.0 & 0.71 & 1.18 & 1.59 & 1.97 & 2.32 & 3.32 & 5.40 & 7.17 & 8.78 & 11.66 & 14.26 & 16.67 & 18.94 & 23.17 & 30.78 & 37.65 & 44.02 \\
\hline 60.0 & 0.76 & 1.30 & 1.78 & 2.23 & 2.65 & 3.81 & 6.24 & 8.33 & 10.23 & 13.65 & 16.76 & 19.64 & 22.36 & 27.45 & 36.63 & 44.96 & 52.70 \\
\hline
\end{tabular}

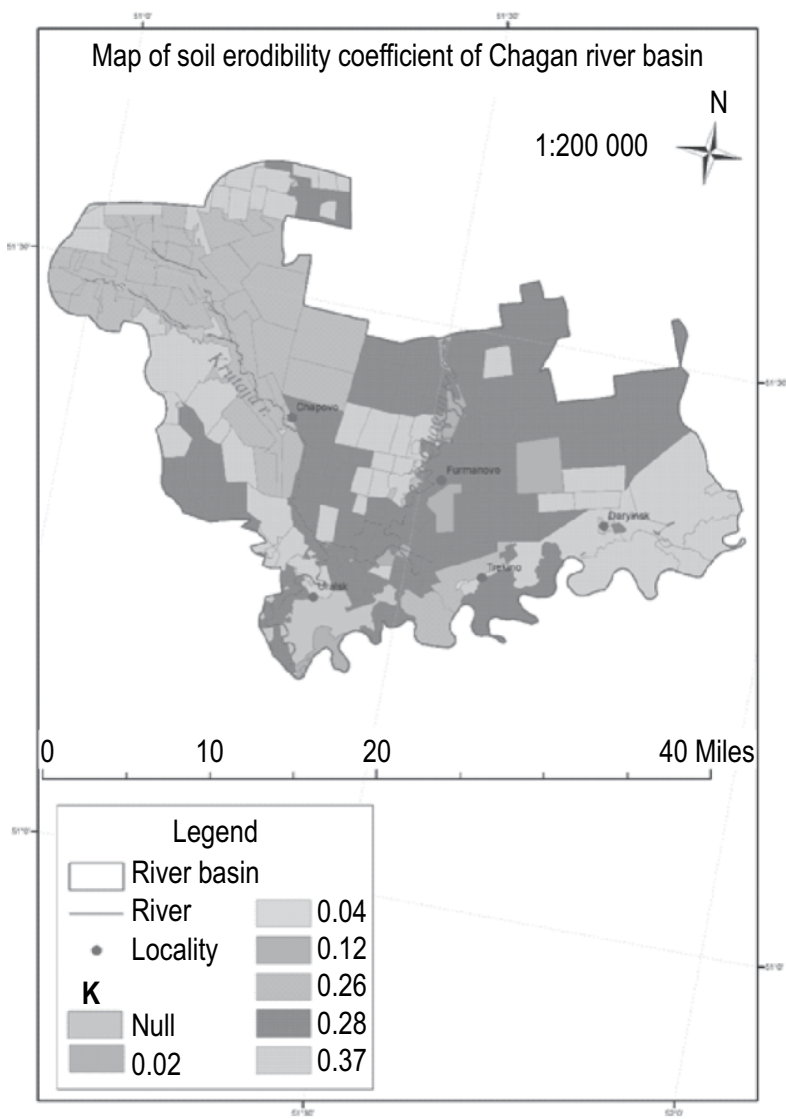

Fig. 3 : Map of soil erodibility coefficient of Chagan river basin.

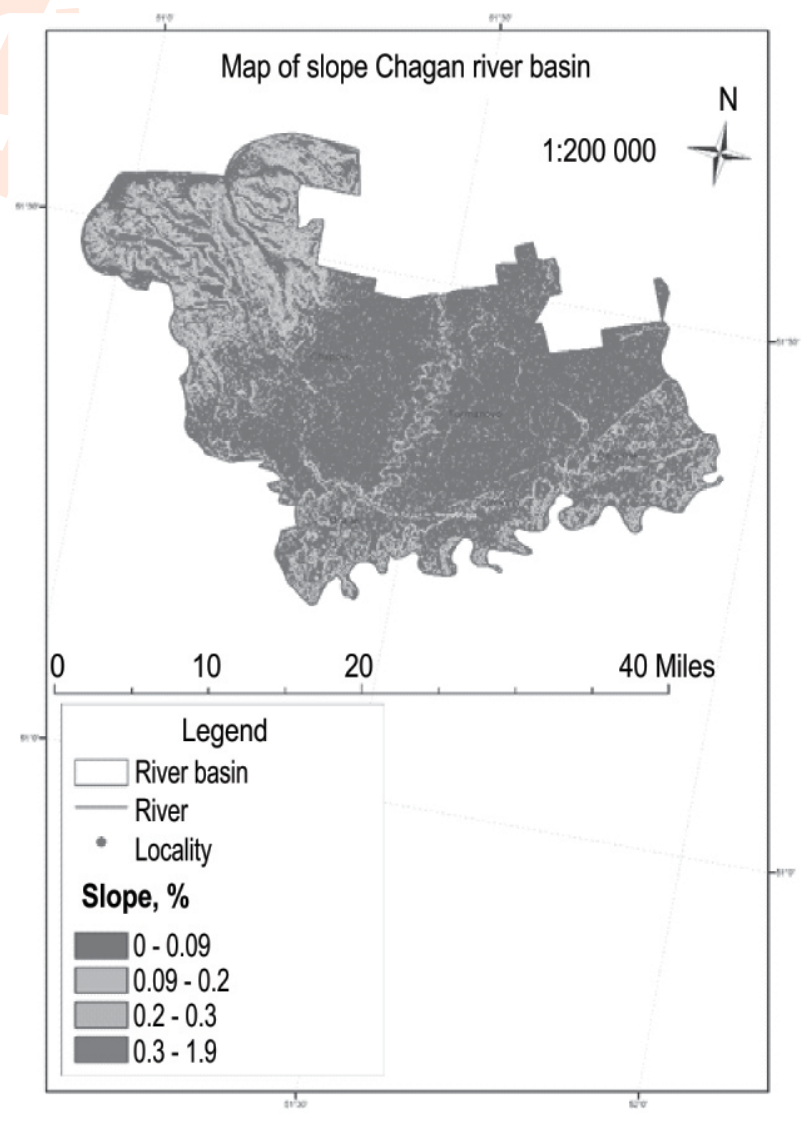

Fig. 4 : Map of Chagan River Basin. 


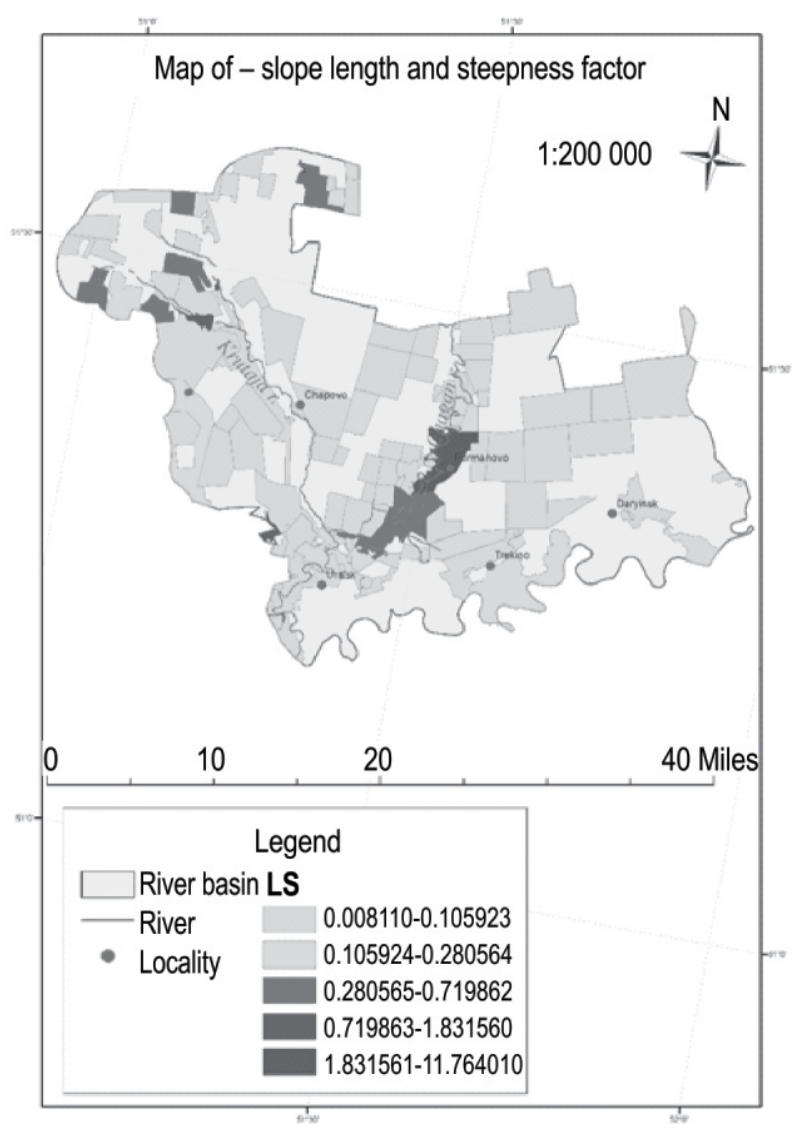

Fig. 5: Map of-slope length and steepness factor.

The basin was divided into 4 categories in terms of gradient of slope (Fig. 4)

Consequently, the values of the Chagan river basin's length was determined using the mapping of the given values in the attribute table and using the Spatial Analyst Tools - Map Algebra- Raster Calculator function. Based on the double value multiplication, we derived the LS factor of the basin (Fig. 5).

As a result of the obtained map, the smallest length and slope steepness of the Chagan river basin is 0.008110 , and the maximum length and slope steepness is 11,764010 . The largest indicator is characteristic for the fields along the Chagan River. After determining the LS factor, we divided the result into 5 categories:

$0.008110-0.105923 ; \quad 0.105924-0.280564 ; \quad 0,280565-$ 0,719862; 0,719863-1,831560; 1,831561-11,764010.

C - Land cover management factor : In this study, Factor $C$ is based on vegetation and low-yield crop areas. Depending on the earth's degradation, the relief is uneven.

Agricultural land maps of the study area were created in program ArcGIS10.1 through the digital reproduction of space

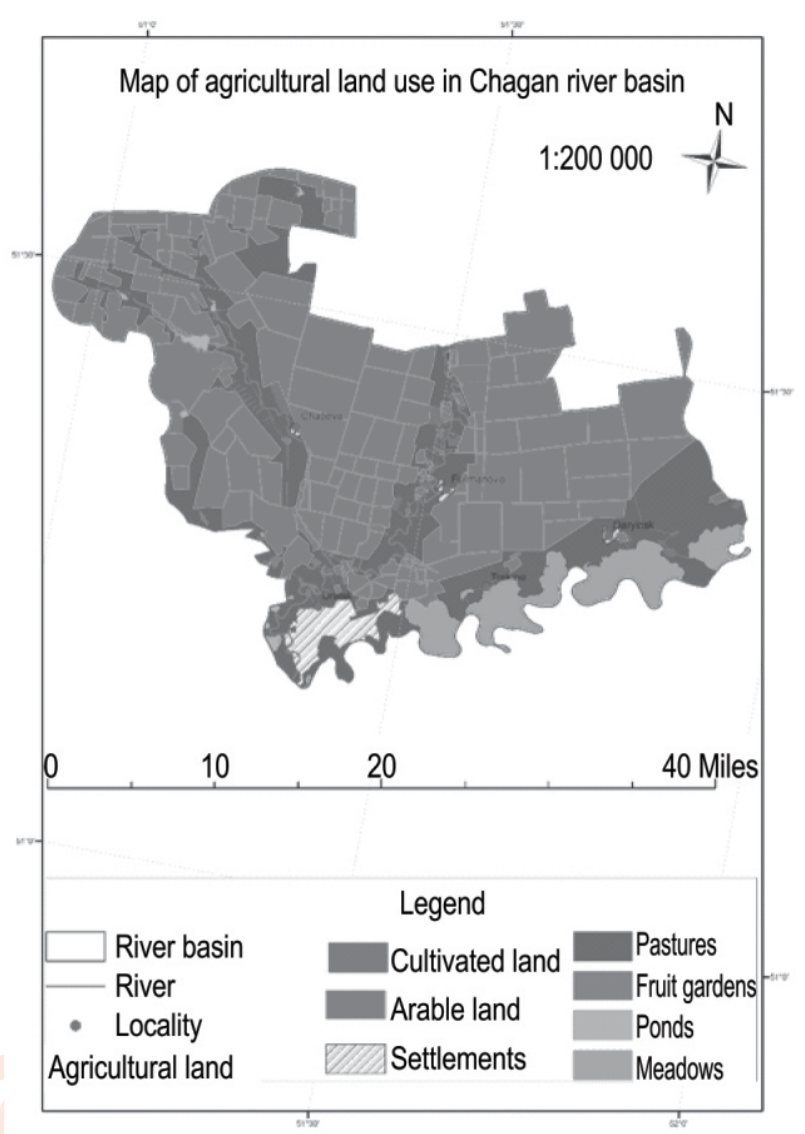

Fig. 6 : Map of agricultural land use in Chagan river basin.

shootings. The study identified seven categories of agricultural land: arable land, pasture, meadows, fruit trees, ponds, settlement and cultivated lands (Fig. 6).

Through analyzing soil vegetation, it is possible to say that arable land is common the Chagan river basin. The majority of arable land is occupied by pure arable land (65\%) and pastures $(25 \%)$, meadows $(6.5 \%)$, fruit gardens $(0.4 \%)$, ponds $(4 \%)$, cultivated land ( $0.6 \%)$ and settlements $(2.4 \%)$.

To calculate factor $C$, we used the information given in the tables (URL, 2). In order to calculate the land cover management, we multiply the values of the type of crops of the cultivated crops by factors of the methods of soil processing, and as a result we determine the coefficient $C$ (Renard et al., 1997). Crops in the garden culture, pastures, milled corn, beans, and fruit trees were included. The methods of soil treatment include the following methods: plowing; plowing without soil, soil cover, special tillage and zero tillage.

Agricultural cultivation factor of soil tillage was increased in order to calculate the land cover management. For example, the coefficient $C$ for pastures is $0.25{ }^{*} 0.02=0.005$; cultivated fields are $0.50 * 0.35=0.175$. In this order, each agricultural land 


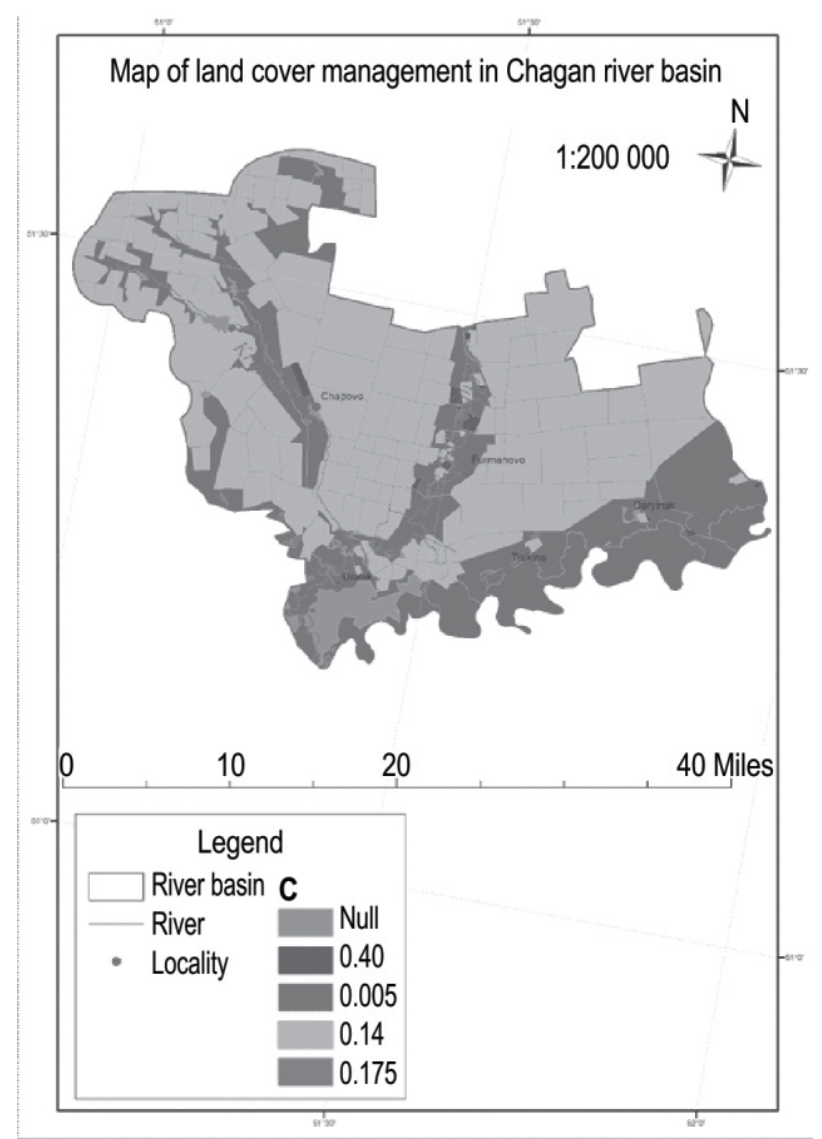

Fig. 7 : Map of land cover management in Chagan river basin.

is given a $C$ factor value and map of land use coefficient in the Chagan river basin (Fig. 7), incorporating the program ArcGIS 10.1 programmatic attribute table.

As a result, the value of the $C$ factor of 0.14 , which occupies $65 \%$ of the array, the value of $C$ factor 0.175 in the fruit and berry gardens occupying $0.05 \%$ of the arable land, 0.005 in the meadow, which occupy $6.5 \% 0.4 \%$ of the ponds had zero value, $0.6 \%$ and $0.40 \%$ and $2.8 \%$ of the arable lands, the $C$ factor was zero.

P - Soil conservation practice factor : Anti-erosion measures or combustion of soil erosion consist of complex work of economic organization, agrotechnical and hydraulic engineering works (Nkonya, 2016). Erosion can only be prevented by the complex application of these activities. Kienzler et al., 2012; Bühlmann et al., 2010)

The following anti-erosion measures are typical for the territory of the Chagan River basin: high and low slopes, horizontal slopes, contouring farming, striped field horizontally sloping and striped field contour.

By calculating the coefficients of all factors in the RUSLE formula, the level of «A» was determined by the Field Calculator
Operation. As a result, the Soil Map is drawn up (Fig. 8).

According to the results, the Chagan River basin weighed 5 categories. Annual soil erodibility up to $0-1.5$ tons per hectare, 0.1-0.5 tha ${ }^{-1} y^{-1}, 0.5-1.2$ tha $^{-1} y^{-1}, 1.2-2.5$ tha $^{-1} y^{-1}, 2.5-13$ tha ${ }^{-1} y^{-1}$. In the central and eastern parts of the basin, the amount of soil erodibility is less than $0.1 \mathrm{t} \mathrm{ha}^{-1} \mathrm{y}^{-1}$. The reason is that in these areas black-brown soils are mechanically composed of mediumglacial and light loam areas.

In $67 \%$ of the Chagan river basin, soil erodibility ranges from 0 to 0.01 ton per hectare, $23 \%-0.1-0.5$ tha $^{-1} \mathrm{y}^{-1}, 5 \%-0.5-1.2 \mathrm{t}$ $\mathrm{ha}^{-1} \mathrm{y}^{-1}$. It was determined that the average annual yield was between $1.2-2.5 \mathrm{t} \mathrm{ha}^{-1} \mathrm{y}^{-1}$ in $3 \%$, and only $2 \%$ of the arable in the range of $2.5-13$ tha ${ }^{-1} y^{-1}$

Minimum soil erodibility indicator No. 1, which has a zero value, is located in dark brown soils; the mechanical composition of the soil is used for the sandy area and pasture. The highest soil erodibility indicator corresponds to the landfill No. 142 per year, at 135 tons per hectare. The reason for this indicator is that the landfill is located in slopes and is used for sowing.

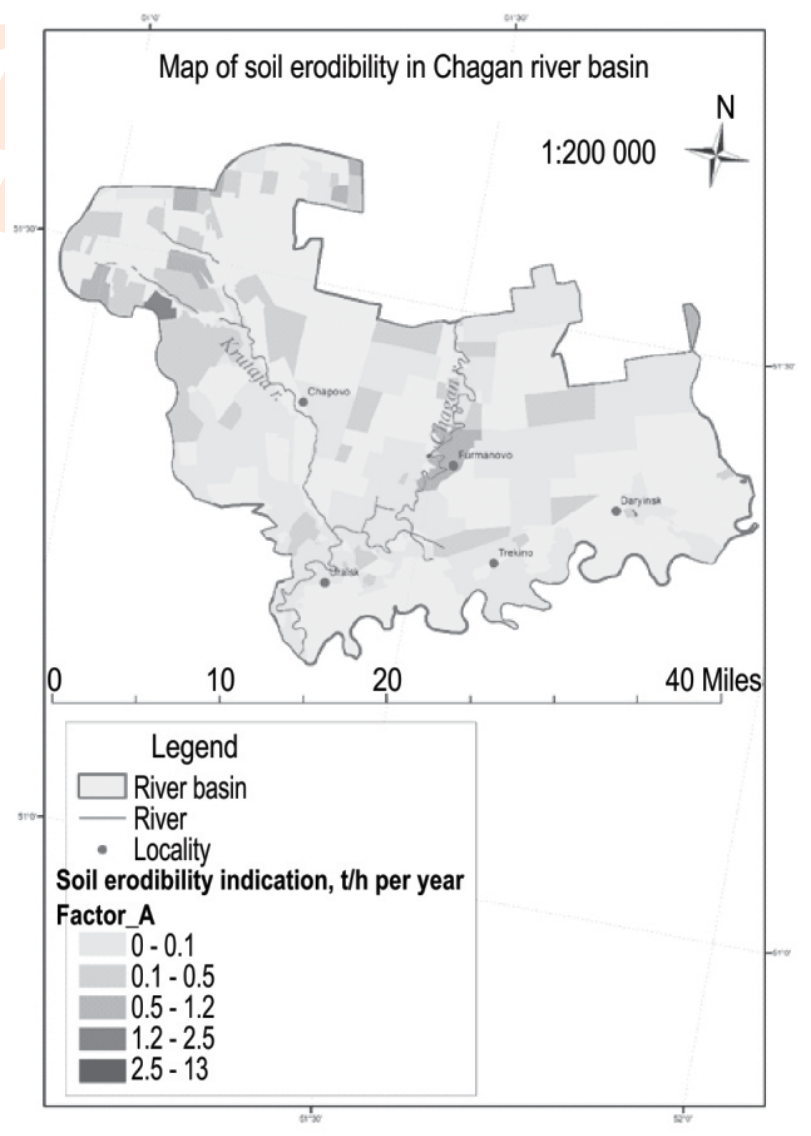

Fig. 8 : Map of soil erodibility in Chagan river basin. 
For example, if we make a change in the $C$ ratio, we will replace "plowing without digging- 0.9 " for "Zero Processing- 0.25 ".

Accordingly, $C$ factor (provided) $=0,50 * 0,25=0.12$. Annual loss of soil erodibility: $=R{ }^{*} K{ }^{*} L{ }^{*} C * P=90 * 0,12 * 1,91$ * $0,12^{*} 0,75=1,9$ tha $^{-1} \mathrm{y}^{-1}$.

In case of changing soil treatment, the average annual loss of soil would be from 3.46 tons per hectare to 1.9 tons per hectare in this area.

As an example, if we change the types of crops that are sown in the field, namely, planting fruit trees instead of grain crops. Consequently, we change the $\mathrm{C}$ factor from 0.40 to 0.10 .

Accordingly, $C$ factor (provided) $=0.10 * 0.25=0.025$. Annual loss of soil erodibility: $=R^{*} K^{*} L S^{*} C^{*} P=90^{*} 0,12 * 1,91$ * $0,025^{\star} 0,75=0,39$ tons per hectare per year.

In case of change of cultivated crops on the sowing, the average annual loss of soil would decrease from 1.9 to 0.4 tons per hectare per year. In general, the annual waste of the tendency of soil erodibility in the Chagan River basin is processed or cultivated in the fields.

The Revised Universal Soil Loss Equation (RUSLE) has enormous potential for integrating remote sensing and Geographical Information System (GIS) technologies for producing accurate and inexpensive assessments of soil erosion. In this study, the RUSLE method was applied to the Esil (Ishim) River basin (ERB), which is situated in Northern and Central Kazakhstan. The northern part of the ERB extends through the Tyumen and Omsk regions of the Russian Federation to the confluence of the Irtysh River. This article may be of interest to experts and specialists in the field of agriculture, as the findings can assist agricultural producers and government entities in making decisions that prevent soil degradation and promote optimal cropping systems for land and crop cultivation. The objective of this research is to detect, estimate and map areas of land plots most vulnerable to potential soil erosion within the ERB, using the RUSLE model under Arc GIS 10.2. The results reveal that average annual soil loss during the study period ranges from 0 to $32 \mathrm{t} \mathrm{y}^{-1}$ and that $108,007.5 \mathrm{~km}^{2}(48 \%)$ of the ERB has no erosion. The remainder of the basin is prone to soil erosion ranging from 1 to $32 \mathrm{tha}^{-1} \mathrm{y}^{-1}$, which comprises $117,216.9 \mathrm{~km}^{2}$ $(52 \%)$, and total soil erosion is $565,368.7 \mathrm{ty}^{-1}$. Soil erosion in the ERB is relatively moderate due to low slope steepness and low annual precipitation (198-397 mm). Exceptions occur in plots which have high slope length steepness, which are scattered throughout the region. However, this study indicated that the watershed is still affected by moderate to very severe erosion rate. Topographic and the vegetation are the most important factors affecting soil loss in rough terrain. These results are in parallel with the results obtained in previous studies (Akiyanova and Vasilchenko 2015; Pashkov and Tayzhanova, 2016; Mueller etal., 2013; Mukanov, 2019).

The formula we implemented in this study was first time used for the territory of the West Kazakhstan region. Since this formula is universal and has been adapted to the natural factors make this study important. Thus, this study can be regarded as unique and interesting.

Counter against soil erodibility is one of the urgency issues of agriculture in the Republic of Kazakhstan. The aim of this study is to determine the tendency of soil erodibility in the Chagan River basin in Kazakhstan. According to the results, the highest rate soil erodibility is in line with the sown area and its average value is equal to 3.46 tons ha-1 $y^{-1}$. Since this figure is significantly higher than the average annual 1.5 tons $h^{-1} \mathrm{y}^{-1}$, we recommend the following changes to prevent soil erodibility.

In general, the tendency of annual loss of soil erodibility in the Chagan River basin is higher in the areas where land is processed or cultivated. Based on the trend of Annual loss of soil erodibility in the Chagan River basin, it has identified the need for preventive and remediation measures. The importance of eradication processes should be thoroughly explored in order to perform erosion prevention effectively.

This study showed that GIS methods allowed accurate definition of spatial distribution of RUSLE parameters. It is also a simple and cheap tool for soil erosion modeling, the risk for erosion potential and risk for the hazardous area that can be difficult to observe on the ground. This model is based on soil stabilization, contour limitations, and so on, as well as additional management practices.

\section{References}

Akiyanova, F.Zh. and N.I. Vasilchenko: Soil erosion and deflation processes in the Akmola region in the conditions of agglomeration development of the region In: Ecosystems of Central Asia in modern conditions of social and economic development. UlanUde, pp. 372-376 (2015).

Amirzhanovna, Z.A., K.M. Zhanaleyeva, B.Z. Galimzhanovich, K.T. Saparov, E.H. Mendybayev and E. Atasoy: Assessment of hydrogeoecological features of the Yesil River Basin. J. Environ. Biol., 38, Special issue, 1115-1120 (2017).

Bargali, S.S., R.P Singh and M. Joshi: Changes in soil characteristics in eucalypt plantations replacing natural broad-leaved forests. J. Veg. Sci., 4, 25-28 (1993).

Bargali, S.S., K. Padalia and K. Bargali: Effects of tree fostering on soil health and microbial biomass under different land use systems in central Himalaya. Land Degrad. Develop., 30, 1984-1998 (2019).

Beisenova, A.S.: Physico-geographical research in Kazakhstan. AlmaAta (2001).

Bigaliyev, A.B., E. Zhamalbekov and P.M. Bildevayeva: Kazakhstan Soil and its Ecology. Almaty, Sanat, pp. 100-118 (1995). 
Borrelli, P., N. Diodato and P. Panagos: Rainfall erosivity in Italy: A national scale spatio-temporal assessment. Int. J. Digit. Earth, 9 , 835-850 (2016).

Bühlmann, E., B. Wolfgramm, D. Maselli, H. Hurni, S.R. Sanginov and H.P. Liniger: Geographic information system-based decision support for soil conservation planning in Tajikistan. J. Soil Water Conserv., 3, 151-159 (2010).

Demczuk, P. and E. Gile: The application of the USLE model in the automatic mapping of soil erosion in the Bystrzanka catchment (Flysh Carpathian). Qua. Geo., 28, 15-25 (2009).

Efe, R., D. Ekinci and I. Curebal: Erosion Analysis of Fındıklı Creek Catchment (NW of Turkey) Using GIS Based on Rusle (3d) Method. Fresenius Environ. Bull., 17, 576-586 (2008).

Efe, R., A. Soykan, I. Cürebal and S. Sönmez: Land use and land cover detection in Karinca River Catchment (Nw Turkey) using GIS and RS Techniques. J. Environ. Biol., Special Issue, 33, 439-447 (2012).

Garifolla, A. and K. Akhmetov: West Kazakhstan, Encyclopedia, Almaty (2010).

Hernando, D. and M.G. Romana: Estimate of the (R) USLE rainfall erosivity factor from monthly precipitation data in mainland Spain. J. Iber. Geol., 42, 113-124 (2016).

lorgansky, A.I. and K.B. Balgabekov: Water and irrigation erosion in Kazakhstan. Kayinar, Almaty (1979).

Kienzler, K.M., J. Lamers, A. McDonald, A. Mirzabaev, N. Ibragimov, O. Egamberdiev, E. Ruzibaev and A. Akramkhanov: Conservation agriculture in Central Asia - what do we know and where do we go from here? Field Crops Res., 132, 95-105. https://doi.org/10.1016 /j.fcr.2011.12.008 (2012).

Mazhitova, G.Z., K.M. Janaleyeva, Z.G. Berdenov, B.B. Doskenova and E. Atasoy: Assessment of the sustainability of landscapes of the North-Kazakhstan region to agricultural impact. News of the National Academy of Sciences of the Republic of Kazakhstan. Ser. Geol. Tech. Scie., 429, 90-95 (2018).

Mendybayev, E.H., G. Atayeva, Zh. Berdenov and E. Atasoy: Geochemical researches of region soil with technogenic influence in terms of Borlinskiy region, West Kazakhstan. Oxid. Commun., 38, 1933-1941 (2015).

Mueller L., A. Saparov and G. Lischeid: Novel measurement and assessment tools for monitoring and management of land and water resources in agricultural landscapes of Central Asia. Springer, Berlin. https://doi.org/10.1007/978-3-319-01017-5 (2013).

Mukanov, Y., Y. Chen, S. Baisholanov, A. Chukwudi, A. Amanambu, G. Issanova, A. Abenova, G. Fang and N. Abayev: Estimation of annual average soil loss using the Revised Universal Soil Loss Equation (RUSLE) integrated in a Geographical Information
System (GIS) of the Esil River basin (ERB), Kazakhstan. Acta Geophys, 67, 921-938 (2019).

Nearing, M.A., S.Q. Yin, P. Borrelli and V.O. Polyakov: Rainfall erosivity: An historical overview. Catena, 157, 357-362 (2017).

Nkonya, E., A., Mirzabaev and J. Von Braun (Eds): Economics of land degradation and improvement: A global assessment for sustainable development. Springer, Berlin, pp. 695. https://doi.org/ 10.1007/978-3-319-19168-3 (2016).

Padalia, K., S.S. Bargali, K. Bargali and K. Khulbe: Microbial biomass carbon and nitrogen in relation to cropping systems in Central Himalaya, India. Curr. Sci. India, 115, 1741-1750 (2018).

Panagos, P. and A. Katsoyiannis: Soil erosion modelling: The new challenges as the result of policy developments in Europe. Environ. Res., 172, 470-474 (2019).

Pashkov, S.V. and M.M. Tayzhanova: Gully erosion determinants in northern Kazakhstan. News of Tula State University. Ear. Sci., 4, pp. 50-63 (2016).

Petek, M., M. Mikoš and N. Bezak: Rainfall erosivity in Slovenia: Sensitivity estimation and trend detection. Environ. Res., 167, 528535 (2018).

Petrenko, A.Z., A.A. Djubanov, M.M. Fartushina, D.M. Chernyshev and Zh. M. Tubetov: The Green Book of the West Kazakhstan region. Uralsk (2001).

Prasad, B., R.K. Jaiswal and H.L. Tiwari: Assessment of environmentally stressed areas for soil conservation measures using USPED model. Int. J. Eng. Res., 3, Special Issue, 58-63 (2014).

Ramazanova N., Zh. Berdenov, S. Ramazanov, N. Kazangapova, S. Romanova, S. Toksanbaeva and J. Wendt: Landscape -geochemical analysis of steppe zone basin Zhaik. News of the National Academy of Sciences of the Republic of Kazakhstan, series of Geology and Technical Sciences, 436, 33-41(2019).

Renard K.G. and J.R. Freimund: Using monthly precipitation data to estimate the R-factor in the revised USLE. J. Hydrol., 157, 287-306 (1994).

Renard K.G., G.R. Foster, D.C. Yoder and D.K. McCool: RUSLE revisited: Status, questions, answers, and the future. J. Soil Water Conser., 49, 213-220 (1994).

Renard, K.G., G.R. Foster, G.A. Weesies, D.K. McCool and D.C. Yoder: Predicting soil erosion by water: A guide to conservation planning with the revised universal soil loss equation (RUSLE). USDA, Agriculture Research Service, Agriculture Handbook, 703, United States Government Printing Office, Washington (1997).

Wischmeier, W.H. and D.D. Smith: Predicting rainfall erosion losses: A guide to conservation planning. USDA, Agriculture Handbook, 537, United States Government Printing Office, Washington (1978). 